\title{
APPLICATION OF MULTIVARIABLE MODEL PREDICTIVE CONTROL (4X4) FOR DIMETHYL ETHER PURIFICATION FROM METHANOL
}

\author{
Abdul Wahid $^{1 *}$, Wildan Raafi Utomo ${ }^{1}$ \\ ${ }^{1}$ Department of Chemical Engineering, Faculty of Engineering, Universitas Indonesia, Kampus UI \\ Depok, Depok 16424, Indonesia
}

(Received: August 2019 / Revised: October 2019 / Accepted: October 2019)

\begin{abstract}
Multi-variable model predictive control (MMPC) was used to control the dimethyl ether (DME) purification process of methanol in the production of DME from synthesis gas. The use of MMPC aims to capture the phenomenon of the interaction between the variables in the process in order to improve the control performance. As the process comprises four input variables and four output variables, MMPC $(4 \times 4)$ is used in this study. The inter-variable interaction is shown in a $4 \times 4$ matrix, where each matrix element is a first-order plus dead-time (FOPDT) model. MMPC $(4 \times 4)$ was tested by changing the set point (SP) and disturbance rejection. The control performance indicators used are integral absolute error (IAE) and integral square error (ISE) and, as a comparison, the control performance of the single-input single-output (SISO) model predictive control (MPC). The results show that MMPC $(4 \times 4)$ is better than MPC in both IAE and ISE. In terms of SP change, MMPC $(4 \times 4)$ is able to significantly improve the control performance of MPC, by $78 \%$ (IAE) and $90 \%$ (ISE). Whereas in the disturbance rejection testing, the improvements in control performance were $58 \%$ (IAE) and $81 \%$ (ISE).
\end{abstract}

Keywords: DME; Methanol; Multi-variable; Predictive; Purification

\section{INTRODUCTION}

Dimethyl Ether (DME) can be used as an alternative energy source. As a propellant, DME is less polluting, naturally degrades easily, has a high cetane number, and does not produce $\mathrm{SOx}, \mathrm{CO}$, and particulate emissions. DME has physical properties similar to those of liquefied petroleum gas (LPG); hence, DME can be used as a substitute for LPG in domestic applications. In addition to this, DME can be used in diesel engines. Because of its wide range of applications, it is important for the large-scale production of DME to be actualized (Marchiona et al., 2008; Solichin et al., 2011; Patil \& Thipse, 2012).

It is very important to obtain and maintain operating conditions at their optimum level so that the desired product can be successfully obtained (Kusrini, 2018). This requires process control so that any disturbances that arise can be handled as well as possible. Likewise, in the production of DME from synthesis gas, proper process control is needed so that the expected product is achieved.

In general, DME is produced via methanol dehydration in a catalytic fixed-bed reactor, followed by a purification process. Wahid and Gunawan (2015) demonstrated the method for determining the control structure of the DME plant designed by Solichin et al. (2011) with the use of a

\footnotetext{
*Corresponding author's email: wahid@che.ui.ac.id, Tel. +62-21-7863516, Fax. +62-21-7863515 Permalink/DOI: https://doi.org/10.14716/ijtech.v10i6.3631
} 
proportional-integral (PI) controller structure. Research on the purification process of this DME production plant was continued by Yanuardi (2015) using an advanced control system that employed single variable model predictive control (MPC). Both the PI control system and MPC system are able to attain zero offset when the SP tracking test and disturbance test are given, but the error value, which uses the integral absolute error (IAE) and integral square error (ISE) as the error calculation, given by these two controls system is still relatively high. This may be caused by the strong interaction between the process variables in the process system. It is possible to manage this problem with the use of a more advanced control system, namely multi-variable model predictive control (MMPC). The use of MMPC can also reduce the total amount of capital investment in the control system by reducing the amount of controller used (Wahid \& Ahmad, 2007).

The MMPC (4×4) used in this study differs from that used by Wahid and Ahmad $(2015,2016)$ because here, only one MMPC is used. Wahid and Ahmad $(2015,2016)$, in contrast, used several MMPCs $(2 \times 2)$ in a multi-model MPC to control the purity of the product from a distillation column. However, the use of one MMPC to control four controlled variables (CVs) is expected to meet the DME purity target in a distillation column.

\section{SIMULATION}

The condition of the DME purification process is based on the DME plant simulation designed by Solichin et al. (2011). DME is purified using a distillation tray column. In this process section, MMPC is used to control four variables, namely the feed column temperature, column condenser vessel temperature, column condenser percent level, and the column bottom stage percent level. This process simulation was carried out using the Aspen HYSYS program as shown in Figure 1.

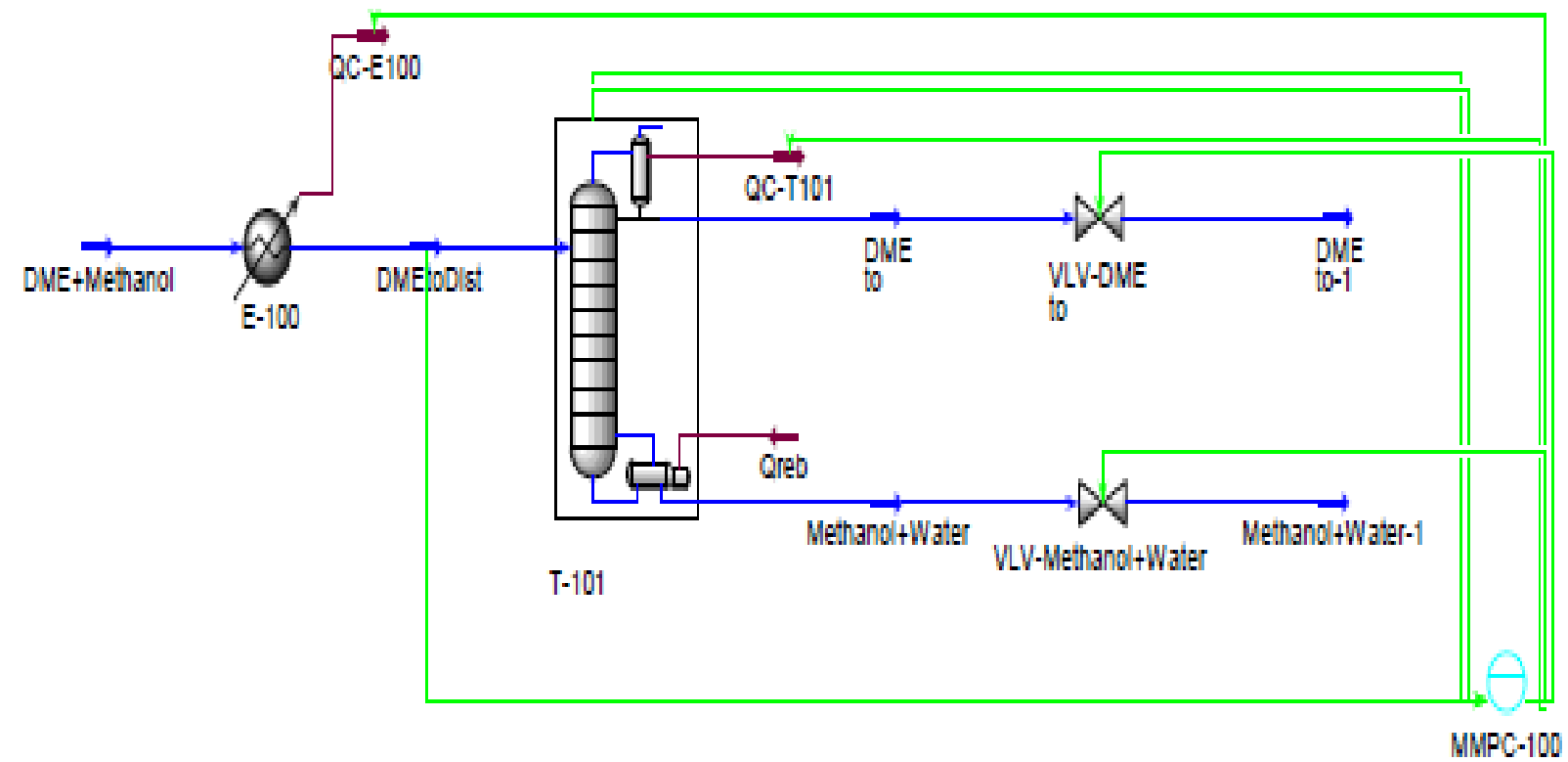

Figure 1 DME \& Methanol Separation Process Scheme with MMPC (4×4)

\subsection{DME and Methanol Separation}

In the DME purification plant, DME will be purified from other mixtures using the distillation column. The product that emerges from the methanol dehydration reactor is a mixture comprising DME, methanol, water, and some unreacted gas (Yanuardi, 2015). The unreacted gas in the product is then purged (Wahid \& Putra, 2018). The DME mixture that will enter the distillation column is in the form of gas; hence, the mixture must be cooled using a precooler prior to it entering the distillation column until it becomes at least a gas and liquid mixture. Table 1 shows 
the specifications of the distillation column, while the operating conditions of the process are shown in Table 2.

Table 1 Distillation column specifications

\begin{tabular}{lc}
\hline \multicolumn{1}{c}{ Parameter } & Value \\
\hline Number of stages (trays) & 8 \\
Stage inlet (stage) & 3 \\
Condenser pressure (psia) & 201.6 \\
Reboiler pressure (psia) & 201.7 \\
\hline
\end{tabular}

Table 2 Distillation stream operating conditions

\begin{tabular}{lccc}
\hline \multirow{2}{*}{ Variable } & \multicolumn{3}{c}{ Value } \\
\cline { 2 - 4 } & Feed & Top Product & Bottom Product \\
\hline Flowrate $($ kgmole/h) & 4354 & 1694 & 2649 \\
Temperature $\left({ }^{\circ} \mathrm{C}\right)$ & 63.51 & 46.12 & 67.36 \\
Pressure $($ psia) & 206.9 & 201.2 & 202.2 \\
DME Fraction $(\%)$ & 43.28 & 99.41 & 9.35 \\
Methanol Fraction $(\%)$ & 43.23 & 0.248 & 21.42 \\
\hline
\end{tabular}

The controller type used in the DME and methanol separation process is an MPC controller. This type of controller can be modified to become a multivariable MPC. The CVs and manipulated variables (MVs) of this process are shown in Table 3.

Table 3 List of CVs and MVs

\begin{tabular}{cll}
\hline No. & \multicolumn{1}{c}{ CV } & \multicolumn{1}{c}{ MV } \\
\hline 1 & Column feed temperature & Precooler heat flow \\
2 & Condenser vessel temperature & Column condenser heat flow \\
3 & Column condenser level & Top product flowrate \\
4 & Column stage volume & Bottom product flowrate \\
\hline
\end{tabular}

\subsection{Multivariable $(4 \times 4)$ Model}

The interactions between each CV and MV in the DME and methanol separation process need to be identified. The system identification results are in the form of FOPDT models, which are obtained by changing the step function in each MV to produce four process reaction curves (PRCs) for the four CVs. Because there are four MVs, 16 PRCs are generated, as shown by Figure 2. The obtained PRCs are converted into FOPDT models using the Smith method (Smith \& Corripio, 1997). All of the transfer functions obtained are then expressed in a $4 \times 4$ matrix to give 16 matrix elements, each of which is an FOPDT model (Corriou, 2017). This matrix functions as an MMPC $(4 \times 4)$, as shown by Equation 1.

$$
\left[\begin{array}{l}
C V_{1}(s) \\
C V_{2}(s) \\
C V_{3}(s) \\
C V_{4}(s)
\end{array}\right]=\left[\begin{array}{llll}
G_{11}(s) & G_{12}(s) & G_{13}(s) & G_{14}(s) \\
G_{21}(s) & G_{22}(s) & G_{23}(s) & G_{24}(s) \\
G_{31}(s) & G_{32}(s) & G_{33}(s) & G_{34}(s) \\
G_{41}(s) & G_{42}(s) & G_{43}(s) & G_{44}(s)
\end{array}\right]\left[\begin{array}{c}
M V_{1}(s) \\
M V_{2}(s) \\
M V_{3}(s) \\
M V_{4}(s)
\end{array}\right]
$$

where $G_{11}(s)$ is a transfer function, for example, which is the process model for $C V_{1}$ and $M V_{1}$ : 

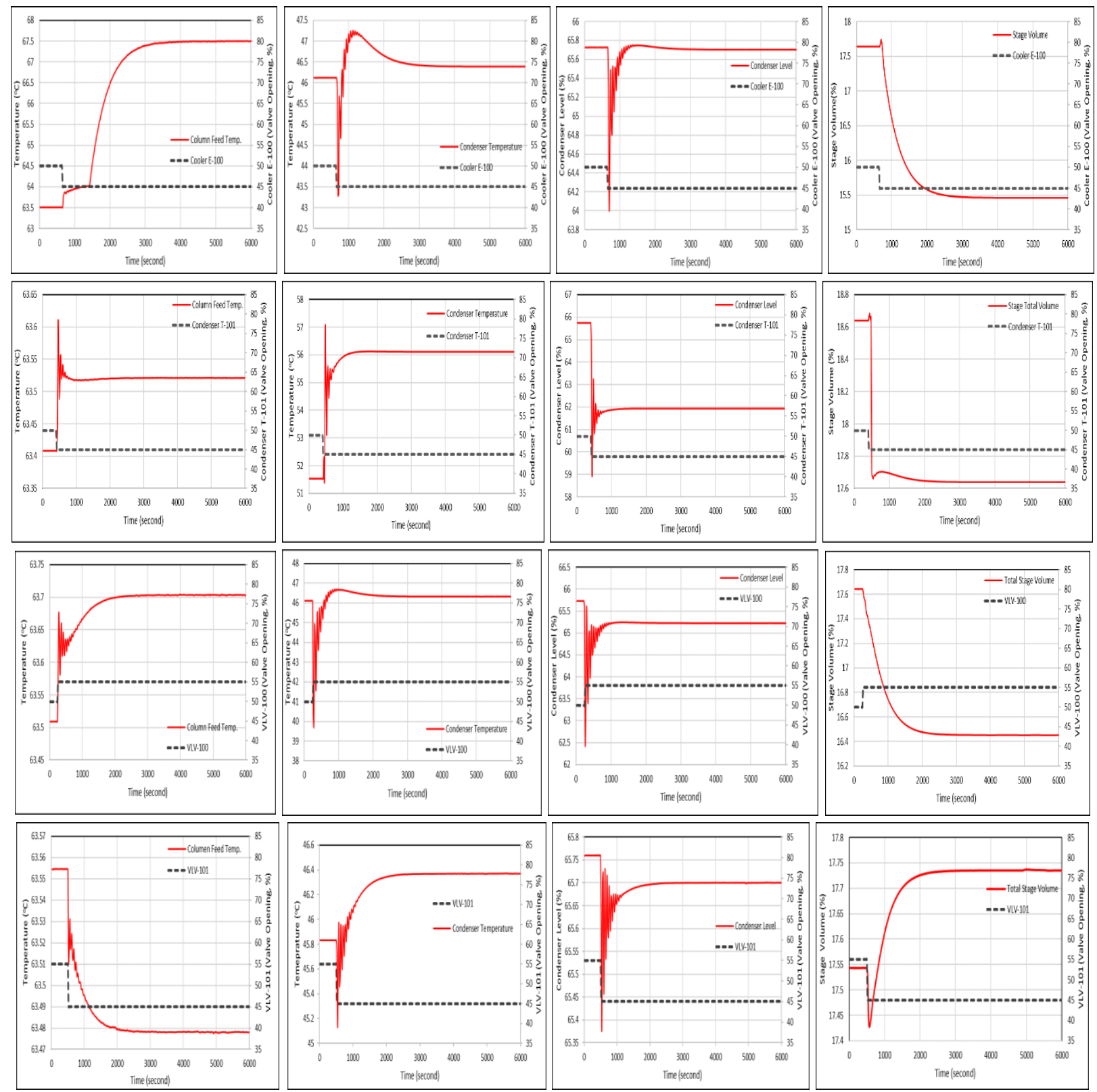

Figure 2 PRCs generated from the MV changes: $1^{\text {st }}$ to $4^{\text {th }}$ row for $M V_{1}$ to $M V_{4}$ changes

$$
G_{11}(s)=\frac{C V_{1}(s)}{M V_{1}(s)}=\frac{K e^{-\theta s}}{\tau s+1}
$$

where $K$ is the process gain, $\tau$ is the time constant, and $\theta$ is dead time (Marlin, 2000).

\subsection{Multi-variable Model Predictive Control Tuning}

Just as in a proportional-integral-derivative (PID) control system, MMPC also has controller parameter values. In an MMPC controller, the value gained from FOPDT is used to calculate the three MMPC parameters of sampling time $(T)$, prediction horizon $(P)$, and control horizon $(M)$. The sampling time is the time interval during which the MVs are being optimized by evaluating new inputs and constraints. The prediction horizon is the number of future control intervals the MPC controller must evaluate by prediction when optimizing its MVs at control interval. Meanwhile, the control horizon is the number of MV moves to be optimized at a definite control 
interval. The values of $T, P$, and $M$ are calculated using the Shridhar and Cooper method (1998), which is shown in Equations 3 to 5 as follows:

- Sampling Time

$$
\begin{gathered}
T_{r s}=\operatorname{Max}\left(0.1 \tau_{r s} ; 0.5 \theta_{r s}\right) \\
T=\operatorname{Min}\left(T_{r s}\right)
\end{gathered}
$$

- Prediction Horizon

$$
P=\operatorname{Max}\left(\frac{5 \tau_{r s}}{T}+k_{r s}\right)
$$

- Control Horizon

$$
M=\operatorname{Max}\left(\frac{\tau_{r s}}{T}+k_{r s}\right)
$$

If the parameter values obtained using the Shridhar and Cooper calculations yield only a nearly good enough controller performance, fine-tuning is carried out with the results obtained from the Shridhar and Cooper method as the initial values of the new controller parameters. This finetuning continues until the optimal parameter value is obtained (Marlin, 2000).

\subsection{MMPC Performance Test Parameter}

To determine whether the tuning result is a good one or not, the performance of the MMPC controller must be tested. The test is carried out either by changing the SP value or adding disturbance to the process and assessing how the CVs respond. In this study, the size of the SP changes and disturbance applied was $5 \%$ of the initial value. After making these changes, the controller performance was determined by calculating the error with the IAE and ISE methods. Equation 8 shows the empirical equation for the IAE method and Equation 9 is for the ISE method. These two error counting methods are commonly used to evaluate the performance of a control system. The calculation results for the IAE and ISE from the MMPC $(4 \times 4)$ control system will be compared to those obtained from the MPC control system designed by Yanuardi (2015) in a previous study.

- Integral Absolute Error (IAE)

$$
I A E=\int_{0}^{\infty}|S P(t)-C V(t)| d t
$$

- Integral Square Error (ISE)

$$
I S E=\int_{0}^{\infty}[S P(t)-C V(t)]^{2} d t
$$

\section{RESULTS AND DISCUSSION}

\subsection{DME and Methanol Separation MMPC $(4 \times 4)$ Model}

Equation 10 shows the 16 FOPDT models $\left(G_{11} \ldots G_{44}\right)$ that resulted from the empirical modeling of the DME purification process from methanol. All of the MMPC $(4 \times 4)$ elements as shown by Equation 1 are represented by a specific transfer function model, and there are no zero-value elements. This shows that all of the MV changes will affect all CVs or that there is an interaction between all CVs and MVs. What is interesting is the effect of the changes in $M V_{2}-M V_{4}$ on $C V_{1}$, which is behind the input variables. Changes in MV should affect only the CV in one piece of equipment and the one in front of it, without no effect on those behind it. However, the system identification shows different results. This is because the feed stream is connected to the inside 
of the distillation column so that any changes in the distillation column will affect the operating conditions in the feed stream.

$$
\left[\begin{array}{l}
C V_{1}(s) \\
C V_{2}(s) \\
C V_{3}(s) \\
C V_{4}(s)
\end{array}\right]=\left[\begin{array}{ccccc}
\frac{-0.129 e^{-0.229 s}}{0.41 s+1} & \frac{-0.014 e^{-0.052 s}}{0.35 s+1} & \frac{0.003 e^{-0.102 s}}{30.60 s+1} & \frac{0.538 e^{-0.081 s}}{24.39 s+1} \\
\frac{0.008 e^{-0.038 s}}{9.66 s+1} & \frac{-0.032 e^{-0.039 s}}{11.84 s+1} & \frac{0.767 e^{-0.033 s}}{9.86 s+1} & \frac{0.008 e^{-0.118 s}}{36.03 s+1} \\
\frac{2.883 e^{-0.079 s}}{23.56 s+1} & \frac{0.767 e^{-0.100 s}}{31.73 s+1} & \frac{-0.188 e^{-0.094 s}}{28.08 s+1} & \frac{-0.369 e^{-0.109 s}}{32.64 s+1} \\
\frac{0.525 e^{-0.035 s}}{10.37 s+1} & \frac{-0.051 e^{-0.055 s}}{16.41 s+1} & \frac{0.002 e^{-0.049 s}}{14.86 s+1} & \frac{0.022 e^{-0.031 s}}{9.37 s+1}
\end{array}\right]\left[\begin{array}{l}
M V_{1}(s) \\
M V_{2}(s) \\
M V_{3}(s) \\
M V_{4}(s)
\end{array}\right]
$$

The sensitivity of an MV to a $\mathrm{CV}$ is shown by the amount of process gain $(K)$. Equation 10 shows that changes to $M V_{1}$ have the greatest effect on $C V_{3}$ and less effect on $C V_{2}$; changes in $M V_{2}$ also greatly affect $C V_{2}$ and have less effect on $C V_{1}$; changes in $M V_{3}$ greatly affect $C V_{2}$ but have less of an effect on $\mathrm{CV} 4$, while changes in $M V_{4}$ exert the greatest influence on $C V_{1}$ but less influence on $C V_{2}$. These results can be used as the basis for $\mathrm{CV}$ and $\mathrm{MV}$ pairing if using SISO-based controllers. However, for greater precision, relative gain array (RGA) analysis can be used (Ajayi \& Ogboh, 2012; Wahid \& Hambali, 2015).

\subsection{MMPC Performance}

The MMPC controller parameter value obtained using the Shridhar-Cooper method is still too imbalanced; hence, some fine-tuning must be carried out. As we can see, the value of $\mathrm{T}$ is too small and the values of $\mathrm{P}$ and $\mathrm{M}$ are too big. In this case, a very large degree of computational effort is required. The result derived from the Shridhar-Cooper method is thus used as an initial value for fine-tuning. Fine-tuning is carried out by adjusting the parameter value up to the point at which the controller gives a proper response. Table 4 shows the results from the ShridharCooper method and the optimum parameter values obtained from fine-tuning (Shridhar \& Cooper, 1998).

Table 4 MMPC $(4 \times 4)$ controller parameter results

\begin{tabular}{lccc}
\hline \multicolumn{1}{c}{ Tuning Method } & $\mathrm{T}$ & $\mathrm{P}$ & $\mathrm{M}$ \\
\hline Shridhar-Cooper & 0.0352 & 5121.84 & 1027.86 \\
Fine Tuning & 25 & 18 & 41 \\
\hline
\end{tabular}

The performance of the tuned controller parameters should then be tested. The optimum controller parameter will result in minimum error. In a multi-model controller, the optimum controller parameter will minimize disturbance due to interaction between the variables. Two types of performance test were carried out, specifically against the change of SP and disturbance rejection. The value of the SP changes and disturbance test was $5 \%$.

\subsubsection{MMPC performance test against change of SP by $5 \%$}

The controller response against an SP change of 5\% is shown in Figure 3. The MMPC controller produced a faster and more stable response compared to the MPC controller response. This is due to the fact that MMPC evaluates the interaction between every $\mathrm{CV}$ and MV whenever there is a change of SP in one of the CVs. Meanwhile, the MPC controller does not evaluate the interactions between any of the CVs and MVs, which means the result is not very satisfying. The increase in controller performance from MPC to MMPC obtained in this study is shown in Table 5. 


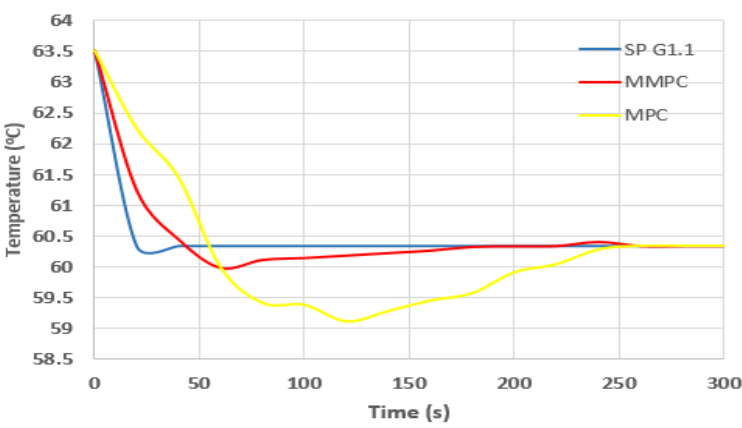

(a)

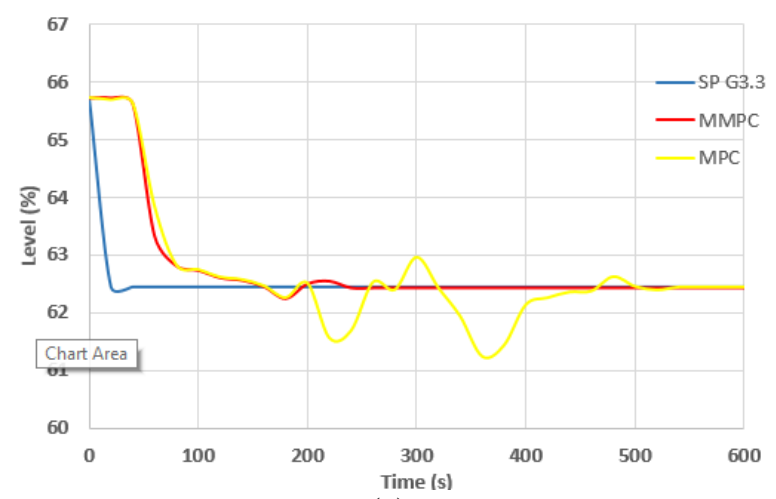

(c)

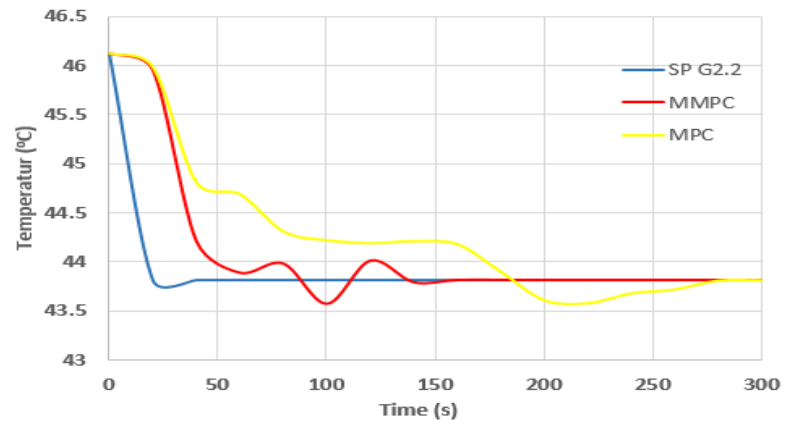

(b)

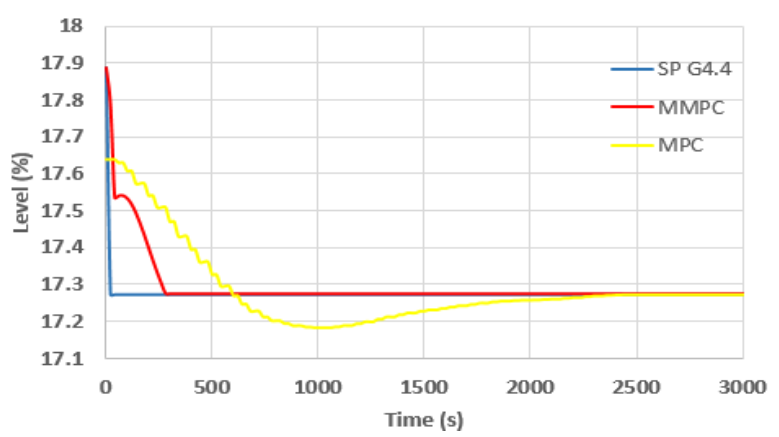

(d)

Figure 3 Test result of 5\% SP change for: (a) column feed temp.; (b) condenser vessel temp.; (c) condenser level; (d) stage total volume

Table 5 Performance comparison between MPC and MMPC with 5\% SP change

\begin{tabular}{lcccccc}
\hline \multirow{2}{*}{ Variable } & \multicolumn{2}{c}{ IAE } & \multicolumn{2}{c}{ ISE } & Improvement & Improvement \\
\cline { 2 - 7 } & MPC & MMPC & MPC & MMPC & IAE (\%) & ISE $(\%)$ \\
\hline Column feed temp $\left({ }^{\circ} \mathrm{C}\right)$ & 200.84 & 44.20 & 222.42 & 21.84 & 77.99 & 90.18 \\
Condenser vessel temp. $\left({ }^{\circ} \mathrm{C}\right)$ & 136.68 & 64.72 & 148.49 & 97.18 & 52.65 & 34.56 \\
Condenser liquid level $(\%)$ & 300.53 & 175.14 & 551.37 & 442.60 & 41.72 & 19.73 \\
Bottom stage total volume $(\%)$ & 164.10 & 53.56 & 35.46 & 14.71 & 67.36 & 58.51 \\
\hline
\end{tabular}

\subsubsection{Disturbance test: feed temperature increased by 5\%}

The results of the disturbance test show that the MMPC controller produced a better response compared to the MPC controller. Figure 4 shows that the MMPC controller responds faster than the MPC controller when disturbance is applied to the system. Table 6 shows the decreasing error that occurred in the system. When controlled by the MMPC controller, all of the CVs yield a smaller error value than when controlled by the MPC controller, thus proving that the MMPC controller is better than the MPC controller in every respect.

Table 6 shows that MMPC $(4 \times 4)$ is better than MPC in both IAE and ISE. With respect to the SP change, MMPC $(4 \times 4)$ is able to improve the control performance of MPC by $78 \%$ (IAE) and $90 \%$ (ISE). Meanwhile, in the disturbance rejection testing, the improvements in control performance were $58 \%$ (IAE) and $81 \%$ (ISE). 


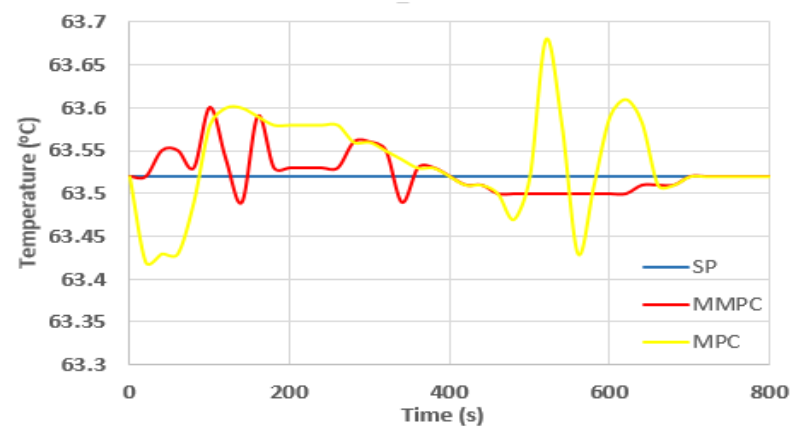

(a)

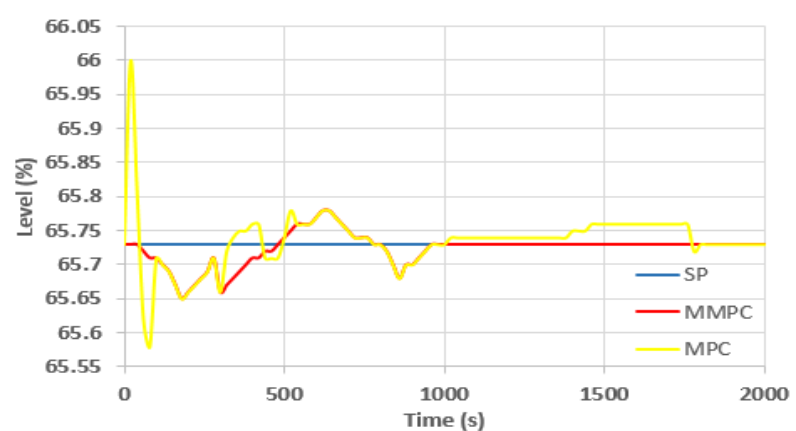

(c)

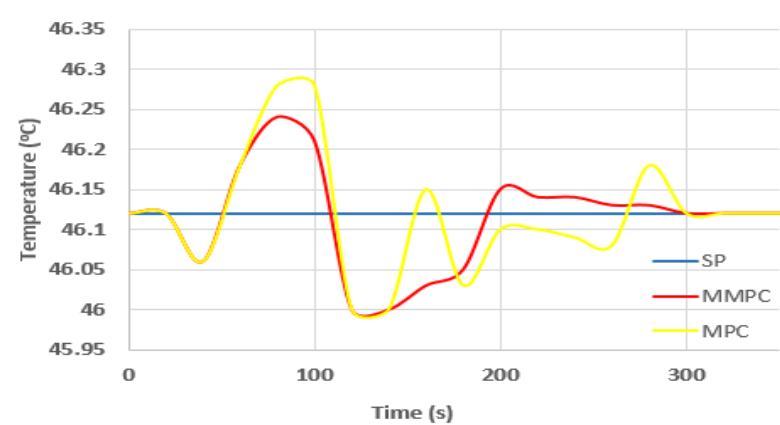

(b)

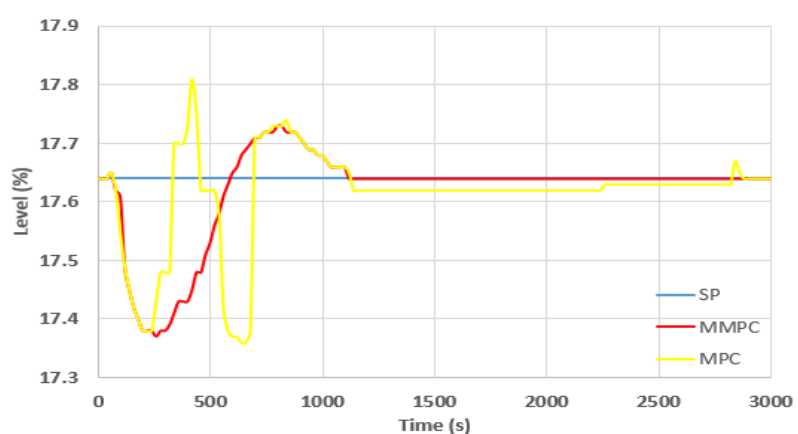

(d)

Figure 4 Test result against 5\% temperature change for (a) column feed temp.; (b) condenser vessel temp.; (c) condenser level; (d) stage total volume

Table 6 Performance comparison between MPC and MMPC with 5\% temperature change

\begin{tabular}{lcccccc}
\hline \multirow{2}{*}{ Variable } & \multicolumn{2}{c}{ IAE } & \multicolumn{2}{c}{ ISE } & Improvement & Improvement \\
\cline { 2 - 7 } & MPC & MMPC & MPC & MMPC & IAE $(\%)$ & ISE $(\%)$ \\
\hline Column feed temp $\left({ }^{\circ} \mathrm{C}\right)$ & 34.06 & 14.2 & 2.58 & 0.49 & 58.31 & 81.01 \\
Condenser vessel temp. $\left({ }^{\circ} \mathrm{C}\right)$ & 19.4 & 16.4 & 2.06 & 1.47 & 15.46 & 28.64 \\
Condenser liquid level $(\%)$ & 53.2 & 27.4 & 3.74 & 1.19 & 48.50 & 68.18 \\
Bottom stage total volume $(\%)$ & 152.6 & 117.4 & 23.27 & 20.87 & 23.07 & 10.31 \\
\hline
\end{tabular}

\section{CONCLUSION}

This study shows that each of the CVs and MVs in the DME and methanol separation process interact with each other. This is indicated by the lack of a zero value inside the MMPC $(4 \times 4)$. This study also shows that MMPC $(4 \times 4)$ is better than MPC with respect to both IAE and ISE. In terms of SP change, MMPC $(4 \times 4)$ significantly improves the control performance of MPC, by $78 \%$ (IAE) and $90 \%$ (ISE). Whereas in disturbance rejection testing, the improvements in control performance were $58 \%$ (IAE) and $81 \%$ (ISE). Thus, while MMPC not only serves as a more effective controller system, it is also more beneficial in terms of the number of controllers used, which will affect capital costs.

\section{REFERENCES}

Ajayi, T.O., Ogboh, I.S., 2012. Determination of Control Pairing for Higher Order Multivariable Systems by the use of Multi-Ratios. International Journal of Scientific \& Engineering Research, Volume 3(3), pp. 1-5

Corriou, J.P., 2017. Multivariable Control by Transfer Function Matrix. In: Process Control: Theory and Applications, (2 ${ }^{\text {nd }}$ ed.), Springer, Cham, Switzerland, pp. 305-338 
Kusrini, E., 2018. Optimizing the Process Conditions in Science and Engineering for Improvement of Product Engineering. International Journal of Technology, Volume 9(2), pp. 212-218

Marchiona, M., Patrini, R., Sanfilippo, D., Migliavacca., G., 2008. Fundamental Investigations on Di-methyl Ether (DME) as LPG Substitute or Make-up for Domestic Uses. Fuel Processing Technology, Volume 89(12), pp. 1255-1261

Marlin, T., 2000. Process Control: Designing Processes and Control Systems for Dynamic Performance International Editions 2000. McGraw-Hill Co., Singapore

Patil, K.R., Thipse, S.S., 2012. The Potential of DME-diesel Blends as an Alternative Fuel for CI Engines. International Journal of Emerging Technology and Advanced Engineering, Volume 2(10), pp. 35-41

Shridhar, R., Cooper, D., 1998. A Tuning Strategy for Unconstrained Multivariable Model Predictive Control. Industrial and Engineering Chemistry Research, Volume XXXVII(10), pp. 4003-4016

Smith, C.A., Corripio, A.B., 1997. Principles and Practice of Automatic Process Control. $2^{\text {nd }}$ Edition., Inc., New York, NY, USA: John Wiley \& Sons

Solichin, A., Sari, M., Rahmiyati, W.Y., Parinduri, 2011. Production of DME from Syngas (for Oxygenates in Diesel Oil and Blending LPG). Plant Design Report, Universitas Indonesia. Depok

Wahid, A., Ahmad, A., 2007. Application of Model Predictive Control (MPC) Tuning Strategy in Multivariable Control of Distillation Column. Reaktor, Volume XI, pp. 66-70

Wahid, A., Ahmad, A., 2015. Min-max Controller Output Configuration to Improve Multi-model Predictive Control when Dealing with Disturbance Rejection. International Journal of Technology, Volume 6(3), pp. 504-515

Wahid, A., Ahmad, A., 2016. Improved Multi-model Predictive Control to Reject Very Large Disturbances on Distillation Column. International Journal of Technology, Volume 7(6), pp. 962-971

Wahid, A., Gunawan, T.A., 2015. Process Control of DME and Methanol Purification in a DME Plant from Synthesis gas. Sinergi, Volume 19(1), pp. 57-66 (in Bahasa)

Wahid, A., Hambali, W.A., 2015. Multi-loop Control Design in Multivariable $(2 \times 2)$ Continuous Stirred Tank Reactor. Sinergi, Volume 19(2), pp. 67-76

Wahid, A., Putra, I., 2018. Multivariable Model Predictive Control Design of Reactive Distillation Column for Dimethyl Ether Production. In: IOP Conference Series. Yogyakarta, 13 September 2018. Materials Science and Engineering, p. 334

Yanuardi, D., 2015. Design of Model Predictive Control System in a Dimethyl Ether Purification Plant and its Economic Analysis. Bachelor Thesis, Universitas Indonesia (in Bahasa) 